\title{
Product Uncertainty in Online Markets: The Influence of Situational Factors and Individual Characteristics on Purchase Decision Reversal
}

\author{
Mayur Jha \\ RWTH Aachen University, \\ Aachen, Germany

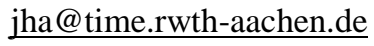

\author{
Jan Kemper \\ RWTH Aachen University, \\ Aachen, Germany \\ kemper@win.rwth-aachen.de
}

\author{
Malte Brettel \\ RWTH Aachen University, \\ Aachen, Germany \\ brettel@time.rwth-aachen.de
}

\begin{abstract}
E-commerce has traditionally suffered from significantly higher product return rates than offline retail (30\% online vs. $10 \%$ offline). Product uncertainty at the time of purchase has been identified as one of the key drivers of purchase decision reversals in online markets.

In this study we analyze the impact of situational factors (1. Purchase channel choice, 2. Time pressure) and individual differences on product uncertainty and purchase decision reversal. Following the conceptualization of product uncertainty by Hong and Pavlou (2014), we distinguish between product fit uncertainty and product quality uncertainty.

To test our hypotheses, we employ a large-scale empirical analysis based on panel data from a large European online fashion retailer. We find that product fit uncertainty is higher for mobile channel users, which is attenuated by prior brand experience. Time pressure leads to lower return rates despite higher product uncertainty.
\end{abstract}

\section{Introduction}

The field of e-commerce has experienced significant growth in sales over the last decade with the fashion segment as one of the main growth drivers [3]. For consumers shopping online has many positive aspects, such as lower transaction costs [54] and increased product selection [22]. On the other hand, consumers cannot inspect the product physically before the purchase, which has been shown to increase uncertainty at the time of purchase $[50,60]$ and the likelihood of product returns [7].

Online retailers on the other hand face a major challenge. Customers expect free returns or will take their business elsewhere. At the same time companies are struggling with stubbornly high return rates.
While return rates in traditional brick-and-mortar shops are lower than $10 \%$, in online stores average return rates exceed $30 \%$ [16, 36, 57]. Product returns pose a significant threat to firms' business models costing businesses a total of USD 100 billion per year through operational costs and lost revenue [53, 59]. Not only do retailers forgo the profit on the original sale, but they also incur operational costs for the reverse logistics and might have to sell the returned product at a reduced price or even discard it.

The cost of returns significantly affects profit margins for retailers. One computation estimates that return rates in excess of $20 \%$ can extinguish the entire profit margin of an online retailer [61].

Apart from the significant cost associated with product returns, they also pose a logistical challenge [65] and potentially reinforce a behavioral loop, in which customers build a return habit [58].

Researchers in marketing and information science (IS) literature have been interested in identifying antecedents to product returns $[4,9,28]$. Five subtopics can be identified: psychological processes, return policy, (firm-controlled and third party) marketing tools, situational factors and individual factors. Past research has focused on psychological processes (e.g. $[4,43,55])$ and return policy (e.g. [25, 29, 31, 38]). Marketing tools, that were examined include website design [28, 59], customer reviews [42, 45] and thirdparty product assurances [12].

Past research revealed that the main cause for increased product returns online is consumer's uncertainty about horizontal and vertical product features $[12,50]$, as they are unable to inspect the product physically before purchasing. The uncertainty construct was conceptualized further to account for the different types of information need and differentiates between seller uncertainty and product uncertainty [12].

However only limited empirical research exists that analyzes the effect of situational and individual factors on product uncertainty and product returns. 
This leads us to the following research questions:

RQ1: How do differences in the purchase situation (1. Purchase channel choice, 2. Time pressure) affect product uncertainty and product returns?

RQ2: Does brand experience mitigate negative effects of the purchase situation on uncertainty and product returns?

With our study we aim to answer researchers calls to identifying "aspects of the online retail transaction [that] make [..] a purchase more return-prone" [23, p. 295]. Furthermore, a large share of research on product returns in the past has been theory-driven or conducted in laboratory-settings. Pavlou et al. [50] suggest that research on product returns should use subjects, that actually buy the focal product. We address this lack of empirical validation using a large-scale data set (873,411 purchased items) from a European onlineonly fashion retailer, with detailed information on consumers transactions, individual characteristics and product return reasons.

Product return reasons can help firms understand consumers pain points across the customer journey and help lower return rates by addressing the issues that lead to product uncertainty. A wide variety of reasons have been identified, why consumers return products, including product failure, damaged product, wrong delivery, incomplete shipments, lower than expected product quality, not being satisfied, and consumer fraud [38]. Nevertheless more than $80 \%$ of product returns being false failure product returns, where the product has no functional or cosmetic defect [37]. In this case consumers realize a lack of product fit only upon post-purchase inspection, which serves a similar role as pre-purchase information $[1,59]$. Nudging is one option to induce favorable behavior, but requires better understanding, which factors influence product uncertainty.

We build on the consumer decision making model by Engel, Blackwell and Miniard [5] and the seminal work of Petersen and Kumar [53] to derive our research framework and apply expectationdisconfirmation theory [48, 49] to develop our hypotheses. Our research contributes to the marketing literature by investigating the influence of unexplored situational and individual factors on product return behavior. Additionally, we contribute to IS literature by analyzing how these factors influence product fit and product quality uncertainty.

\section{Conceptual Framework}

\subsection{Literature Review}

One of the earliest conceptualizations of product returns in marketing literature was in the consumer behavior models Engel, Kollat and Blackwell [14], where it is conceptualized as a post-purchase decision process. Compared to the pre-purchase phase, theory development and concept building has historically lagged behind for the post-purchase stage $[19,53]$.

In e-commerce product returns are substantially more common than in stationary retail as consumers do not have the opportunity to experience the product physically before making their purchase decision [11] and the majority of product returns online has been found to be related to negative post-purchase product evaluations [45].

Minimizing return rates is in the best interest of online retailers and has been a key topic in research on return behavior. Since various researchers have shown that restrictive return policies are detrimental to sales, profits and customer lifetime value (CLV) [52, 53], the majority of retailers opt for lenient return policies [31]. Researchers have therefore called for a better understanding of the antecedents of product return behavior, focusing on individual differences $[4,9,53]$ and add empirical validation to the existing theoretical concepts[60].

In recent years product returns have also found growing attention in IS literature, where products returns are conceptualized as an information problem, which helps to explain why return rates are significantly higher online than offline. In online markets return rates depend on the amount of information available to the consumer at the time of purchase and the remaining uncertainty about the product at the time of purchase $[12,28]$. Because online shoppers cannot assess all properties of the purchased product they face higher uncertainty about the products performance and quality [13, 62]. Past research has focused on identifying which role information plays in lowering perceived uncertainty at the time of purchase and the effect on product return rates. Type and source of information play a significant role in determining return rates, with visual information, such as pictures and videos, and thirdparty provided information being able to significantly reduce return rates $[9,45]$. The amount of information also affects return rates, but the direction of the effect depends on the information needs of the consumer [21, 59].

Consumer uncertainty in online marketplaces can be distinguished between seller uncertainty and product uncertainty $[12,20]$. While seller uncertainty has already received significant attention in the past (e.g. $[12,20,51])$ this study will focus on product uncertainty, which has been shown to have a greater effect than seller uncertainty in online settings [12]. 
Product uncertainty can further be distinguished between product fit uncertainty and product quality uncertainty [28]. Product quality uncertainty refers to the inability of consumers to predict the future performance of the product, while product fit uncertainty describes the consumers' difficulty to assess the fit between the product's attributes and their personal preferences. For products such as apparel the purchase decision depends strongly on the fit between product attributes and personal preferences [25], but fit is only fully revealed at the time of post-purchase inspection, as it includes experiential product attributes $[10,28]$. Several antecedents of product uncertainty in online marketplaces have been examined by IS researchers. Third-party evaluations, multimedia visual product representation and word-of-mouth platforms have been found to significantly reduce product uncertainty [12, 28].

Researchers have called for further investigation into the effect of internet enabled systems on product uncertainty $[28,56]$.

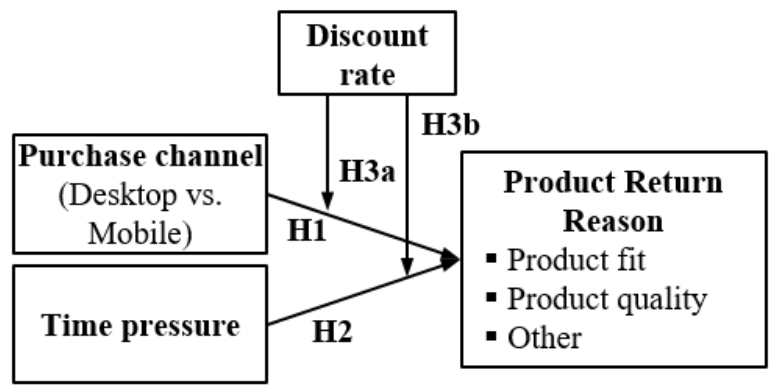

Controls:

Age, Gender, Number of prior purchases, Basket size, Discount rate

Figure 1. Res earch model

Figure 1 shows the underlying research model. According to Engel, Blackwell and Miniard [5] and Kumar and Petersen [53] the purchase situation is the key antecedent that determines post-purchase behavior and return decisions, while individual differences, such as past purchase behavior and customer characteristics moderate the relationship. The situational factors examined in this research are purchase channel choice and time pressure. Time pressure has been shown to significantly influence decision making behavior as it affects decision heuristics and perceived quality of the decision [44]. Channel choice (here: mobile vs. desktop) is known to influence purchase behavior as well as return rates [41]. As a moderator we investigate the influence of brand experience. Product familiarity has been shown to reduce product fit uncertainty [28], but the interaction effects of prior consumer knowledge with situational purchase characteristics is not yet known.

\subsection{Theory and Hypothesis Development}

2.2.1. Expectation-disconfirmation theory. To establish the theoretical link between purchase situation, uncertainty and product returns we apply expectation-disconfirmation (ED) theory $[48,49]$, which has been heavily utilized in the fields of marketing and information sciences.

Several studies have identified customer dissatisfaction with the product as the key antecedent for product returns [32, 38]. Dissatisfaction can (but does not have to) lead to a complaint reaction, such as negative word-of-mouth, redress seeking or product returns [32]. In most of the situations dissatisfaction is triggered by a mismatch between the product features and consumer's individual needs [7].

According to the ED model, consumers form an expectation towards the product's performance and quality at the time of purchase and subsequently perform a post-purchase evaluation, where they compare these expectations with the perceived product quality. When actual performance is lower than expectations consumer's expectations are disconfirmed. Consumer's satisfaction with a purchase is a function of both disconfirmation of expectations and actual performance [48, 49]. Interestingly it has been found that disconfirmation dominates expectations as a predictor for customer dissatisfaction [35]. Consumer are only willing to accept a disparity between expectations and actual performance up to a certain point [2].

Uncertainty at the time of purchase increases the probability of expectation disconfirmation and therefore the likelihood of product returns [35].

\subsubsection{Hypotheses generation.}

Past research has found that consumers who use mobile devices are exposed to a different information format and provide customers with less flexibility and smaller screen sizes. [47]. As a result, consumers are exposed to higher search cost to retrieve relevant information on mobile devices [21] and are therefore expected to collect less information before making their purchase decision [23].

Fit uncertainty is a direct outcome of consumers inability to assess their own preferences and the inability to assess the true nature of the product features[28]. In the case of mobile channel use we argue that consumers inclination to gather less information will expose them to higher fit uncertainty. At the same time we expect consumers with less 
information to form lower expectations [60]. The increase in fit uncertainty at the time of purchase increases the probability of expectationdisconfirmation at the time of post-purchase inspection and leads us to our hypothesis:

H1a: Mobile channel use has a positive relationship to fit related product returns.

Product quality uncertainty arises when product quality cannot be sufficiently assessed by the customer [50]. While website technologies (e.g. pictures, zoom, color swatch) have been found to reduce product fit uncertainty $[9,28]$, insights on the effect on product quality uncertainty remain sparse. Past research suggests that product quality is difficult to observe [33] and consumers rely on signals, such as price or brand reputation for their judgement and expectation formation [33]. For this reason we assume, that product quality uncertainty is not affected by channel choice. Since expectations are lower in the mobile channel with consumers gathering less information, we hypothesize:

H1b: Mobile channel has a negative relationship to quality related product returns.

Time pressure affects decision making not only in the amount of information collected, but also leads consumers to concentrate more on negative information [27] and can shift the salient attributes on which consumers base their decision [34]. Furthermore, consumers shift to a non-systematic information processing mode under time pressure to abbreviate the information processing and decision making stage [44]. Overall customers collect less (useful) information and base their purchase decision on non-optimal heuristics, such as the satisfycing heuristic [34]. Therefore, we argue that, under time pressure consumers will stand a higher risk to experience product fit and product quality uncertainty at the time of purchase.

At the same time, time pressure also has a strong influence on expectations. Under time pressure decision-makers consider their decision to be of less quality [44]. As a result, we expect consumers expectations to be significantly lower under time pressure.

At the time of post-purchase evaluation, we expect lowered expectations to result in less disconfirming experiences, that would lead to a decision reversal, in spite of the increased product uncertainty they are exposed to.
H2a: Consumers who purchase under time pressure return fewer items due to product fit reasons.

H2b: Consumers who purchase under time pressure return fewer items due to product fit reasons.

Brand experience could mitigate the effect purchase channel and time pressure have on product uncertainty and return decisions. Customers that have repeatedly purchased a given product from the same brand have a higher brand loyalty [30], are more satisfied with the product consumption experience and will increase their share-of-wallet for this brand [8]. We therefore conclude that consumers with brand experience are more aware of their preferences and the product attributes than consumers without brand experience. In this case consumers with brand experience would be exposed to less product fit uncertainty. Therefore, we hypothesize:

H3a: Brand experience is negatively related to returns due to product fit reasons.

We are also interested in the interaction effects of brand experience with the situation factors purchase channel and time pressure. In the case of channel use, we expect mobile channel shoppers to benefit more significantly from brand experience than non-mobile customers. Mobile channel is expected to increase product fit uncertainty as customers collect less relevant information [21]. With prior brand experience we argue that customers will require less product information in the first place. Collecting less information would then have a less detrimental effect on product uncertainty. Therefore, products returns due to unsatisfactory fit will also be less likely, leading us to following hypothesis:

H3b: The negative effect of brand experience on product fit related returns is stronger for consumers in the mobile channel.

With a similar logic we argue that brand experience also interacts with time pressure. Under time pressure consumers have difficulty to collect and process product information sufficiently well. With brand experience their information need to reduce product fit uncertainty would be significantly reduced so that we hypothesize:

H3c: Brand experience reduces product fit related returns more significantly when consumers are purchasing under time pressure.

\section{Data \& Methodology}


Our key goal is to answer the research questions empirically for consumers in a real-life shopping situation. The data consists of panel data for customers of a large online-only fashion retailer from Europe with a sales volume of over EUR 1 billion per year.

The data set includes all transactions between January, 1 1st, 2017 and December 31st, 2017 for a random sample of 100,000 customers, who purchased $\sim 873,411$ items and returned $\sim 528,151$ items in 39 different product categories (e.g. jeans, sneaker) and more than 500 brands along two different sales channels (desktop, mobile).

The purchase channel was defined as a binary variable, where we distinguish between mobile and desktop devices. While the decision-making process can consist of multiple website visits through both mobile and desktop devices, the information about the device is collected at the time of purchase. Accessibility of information has a strong influence on decision reversal [4]. Being the information format viewed by consumers at the time of making their purchase decision, we assume it is the most influential.

Time pressure is operationalized by identifying all purchases, in which customers had selected the paid option for an expedited delivery.

While faster delivery is an appreciated element of the purchase experience [64], customers are reluctant to pay for shipping [56]. In order to exclude customers, who opt for express delivery without actual time pressure, we have excluded all purchases, where customers opted for express delivery in their previous purchase as well.

Brand experience has been widely studied in business research. For operationalization we use customers' prior purchase data (365 days prior to purchase) to identify if they have recent experience with the purchased brand in the category of purchase.

Return reasons are provided by consumers in the event of a product return on a voluntary basis. The return reason expresses the primary reason of dissatisfaction that triggered the purchase decision reversal [18]. For operationalization we utilize the categories proposed by leading papers on uncertainty as an antecedent of product returns, which distinguish between product fit uncertainty and product quality uncertainty [12]. Instead of measuring uncertainty on (survey-based) primary data, this study uses the stated return reason and measures the dominating source of uncertainty.

The return reason is inquired by the retailer for each returned item, where consumers can select out of 9 different options provided by the retailer. The return reason can be classified into product fit related returns, product quality related returns and other (mostly service-related returns). It should be noted that $\sim 30 \%$ do not state any return reasons. An independent t-test was performed for all explanatory variables and confirmed that no significant difference existed between respondents and non-respondents. We assume there is no significant response bias due to social desirability. Consumers are generally aware of return policy leniency [31] and understand that their product return is accepted independent of the reason stated.

Individual differences have a strong influence on purchasing behavior and the post-purchase experience $[15,39]$. We therefore control for customer characteristics, such as age and gender. Additionally, we control for basket size and order count. Order count measures the number of orders the customer has placed with the retailer before the purchase. Over time consumers get more comfortable and experienced ordering from a certain retailer online [53], leading to higher sales, higher repurchase intentions and less time spent per order [6]. In fact, Shah et al. [58] found that several aspects of purchasing behavior, including return behavior changes over time.

\section{Results}

Table 1 shows the regression results including interaction effects between the two explanatory variables (Purchase channel and time pressure) with the moderator brand experience. We report the regression coefficients $b_{i j}$, the corresponding standard deviation $\sigma_{i j}$ and the significance for each coefficient. The parameters reported in a multinomial logistic regression compare the change in probability of pairs of outcome categories, when the independent variable is manipulated. Results are reported separately for the outcome categories Product fit, Product quality and Other, while No return serves as the baseline category.

As hypothesized in $\mathrm{H} 1 \mathrm{a}$ product returns due to product fit are positively correlated with purchasing in the mobile channel. H1b is also supported by the data. Returns due to quality unfit are significantly lower in the mobile channel. Purchasing under time pressure has a substantial and significant effect on product returns due to product fit and product quality. As hypothesized in $\mathrm{H} 2 \mathrm{a}$ and $\mathrm{H} 2 \mathrm{~b}$, return rates go down significantly under time pressure for both product fit dissatisfaction and product quality dissatisfaction.

As a direct effect brand experience is negatively related to returns due to product fit and product quality $(\mathrm{p}<0.001)$ and shows relatively large effects sizes $\left(\mathrm{OR}^{1}=0.824\right.$ and 0.838$)$, while no significant effect is

\footnotetext{
${ }^{1}$ Odd's ratio (OR) is measure for the effect size. It describes the increase in probability for an outcome $\mathrm{Y}_{\mathrm{i}}$, when the explanatory variable is increased by one unit. An overview of all Odd's ratios for both regression models is given in Table 2 .
} 
observed for other return reasons. As discussed in the conceptual framework we are more interested in the interaction effect between brand experience and the situational variables. We hypothesized that brand experience would have a negative moderating effect for all purchase situations $(\mathrm{H} 3 \mathrm{~b}-\mathrm{c})$. This hypothesis was not supported by the logistic regression. Hence only $\mathrm{H} 3 \mathrm{a}$ and $\mathrm{H} 3 \mathrm{c}$ can be confirmed.

The control variables selected for the model all show significant effects. Table 2 gives a full overview of the odd's ratios for both models.

Table 1. Regress ion coefficients for MLR with interaction effects

\begin{tabular}{|c|c|c|c|}
\hline Variable & $\begin{array}{c}\text { Product } \\
\text { fit } \\
\end{array}$ & $\begin{array}{c}\text { Product } \\
\text { quality }\end{array}$ & Other \\
\hline Intercept & $\begin{array}{l}-0.160^{* * * *} \\
(0.006)\end{array}$ & $\begin{array}{l}-3.62 * * * \\
(0.022)\end{array}$ & $\begin{array}{l}-4.084^{* * * *} \\
(0.030)\end{array}$ \\
\hline \multicolumn{4}{|l|}{ Explanatory variables } \\
\hline Purchase channel & $\begin{array}{l}0.0059 \\
(0.005)\end{array}$ & $\begin{array}{c}-0.068 * * * * \\
(0.020)\end{array}$ & $\begin{array}{l}-0.016 \\
(0.026)\end{array}$ \\
\hline Time pressure & $\begin{array}{l}-0.289 \text { *** } \\
(0.020)\end{array}$ & $\begin{array}{l}-0.185^{*} \\
(0.078)\end{array}$ & $\begin{array}{c}0.005 \\
(0.095)\end{array}$ \\
\hline \multicolumn{4}{|l|}{ Interaction effects } \\
\hline Brand experience & $\begin{array}{c}-0.194 * * * * \\
(0.008)\end{array}$ & $\begin{array}{c}-0.176 * * * \\
(0.032)\end{array}$ & $\begin{array}{l}-0.070 . \\
(0.042)\end{array}$ \\
\hline $\begin{array}{l}\text { Purchase channel } \\
\text { x Brand experience }\end{array}$ & $\begin{array}{c}0.060^{* * * *} \\
(0.012)\end{array}$ & $\begin{array}{c}0.056 \\
(0.000)\end{array}$ & $\begin{array}{l}0.123^{*} \\
(0.060)\end{array}$ \\
\hline $\begin{array}{l}\text { Time pressure } \\
\text { x Brand experience }\end{array}$ & $\begin{array}{c}-0.121^{* *} \\
(0.043)\end{array}$ & $\begin{array}{l}-0.049 \\
(0.170)\end{array}$ & $\begin{array}{l}-0.153 \\
(0.215)\end{array}$ \\
\hline \multicolumn{4}{|l|}{ Control variables } \\
\hline Order count & $\begin{array}{c}0.004 * * * * \\
(0.000)\end{array}$ & $\begin{array}{c}0.004 * * * \\
(0.000)\end{array}$ & $\begin{array}{c}0.003 * * * \\
(0.000)\end{array}$ \\
\hline Age & $\begin{array}{c}-0.169 * * * \\
(0.005)\end{array}$ & $\begin{array}{c}-0.320 * * * * \\
(0.018)\end{array}$ & $\begin{array}{c}-0.332^{* * * *} \\
(0.024)\end{array}$ \\
\hline Gender & $\begin{array}{l}-0.340^{* * * *} \\
(0.006)\end{array}$ & $\begin{array}{c}-0.423 * * * \\
(0.024)\end{array}$ & $\begin{array}{c}-0.346^{* * * *} \\
(0.031)\end{array}$ \\
\hline Discount rate & $\begin{array}{c}0.003 * * * \\
(0.000)\end{array}$ & $\begin{array}{c}0.006^{* * * *} \\
(0.000)\end{array}$ & $\begin{array}{c}0.005^{* * * *} \\
(0.001)\end{array}$ \\
\hline Basket size & $\begin{array}{c}0.002 * * * * \\
(0.000)\end{array}$ & $\begin{array}{c}0.002 * * * \\
(0.000)\end{array}$ & $\begin{array}{c}0.002 * * * \\
(0.000) \\
\end{array}$ \\
\hline $\begin{array}{l}\text { McFadden } R^{2}: \\
\text { Likelihood ratio test: }\end{array}$ & $\begin{aligned} & 0.04 \\
= & 56137(p\end{aligned}$ & $\left.10^{\wedge} 9\right)$ & \\
\hline
\end{tabular}

\section{Discussion}

\subsection{Key findings}

Product returns in online markets has been a widely studied topic in recent years and antecedents have been covered. Nevertheless, situational factors and individual differences have been suspiciously absent. This could be due to limited ability for firms to influence them. Our study has taken a step towards addressing this shortcoming in the literature by analyzing the effect of purchase channel choice, time pressure and brand experience on product return behavior.

Our first hypothesis proposed that customers who purchase items in the mobile channel are more likely to return products due to fit related reasons, but less likely to return items due to quality related reasons. Our results offer support for this hypothesis. Due to higher search cost in the mobile channel [21] we suggested consumers collect less information and are exposed to a higher product fit, but product quality uncertainty remains the same. This is because product information in fashion retail is almost exclusively designed to reduce fit uncertainty, such as pictures, sizing advice and similar style suggestions. The negative relationship between mobile channel use and quality related returns is explained with the reduced expectations consumers form, as they collected less information during the time of purchase.

Secondly, we hypothesized that time pressure is associated with lower product returns related to fit or quality reasons. This hypothesis was also supported by our results. The large effect size for both fit and quality related returns $(-27 \%$ and $-18 \%)$, suggests that lower expectations, which are common after decision under time pressure [44], could be a powerful driver to reduce product returns.

Our third hypothesis suggested that brand experience had a direct negative effect on fit-related product returns, which was also supported by our results. With prior brand experience consumers face less uncertainty at the time of purchase, as they were able to experience the product holistically in various dimensions and have lower information needs as a result.

Furthermore, we proposed the existence of a moderation effect of brand experience on the relationship between situational factors and fit-related product returns. We argued that brand experience would ameliorate fit uncertainty in the mobile channel and under time pressure. In both situations consumers are typically basing their decision on less information. Nevertheless, we found that in the mobile channel brand experience further increases fit related return rates. Hypothesis $\mathrm{H} 3 \mathrm{~b}$ therefore must be rejected. Under time pressure brand experience had the expected effect to further decrease product return rates. H3c was supported by our results.

Furthermore, we proposed the existence of a moderation effect of brand experience on the relationship between situational factors and fit-related product returns. We argued that brand experience would ameliorate fit uncertainty in the mobile channel 
and under time pressure. In both situations consumers are typically basing their decision on less information. Nevertheless, we found that in the mobile channel brand experience further increases fit related return rates. Hypothesis $\mathrm{H} 3 \mathrm{~b}$ therefore must be rejected. Under time pressure brand experience had the expected effect to further decrease product return rates. H3c was supported by our results.

Table 2. Odd's ratios for MLR models

\begin{tabular}{|c|c|c|c|}
\hline Variable & $\begin{array}{c}\text { Product } \\
\text { fit }\end{array}$ & $\begin{array}{c}\text { Product } \\
\text { quality }\end{array}$ & Other \\
\hline \multicolumn{4}{|l|}{ Model 1 (Direct effects): } \\
\hline Intercept & 0.848 & 0.027 & 0.017 \\
\hline \multicolumn{4}{|l|}{ Explanatory variables } \\
\hline Purchase channel & 1.018 & 0.945 & 0.962 \\
\hline Time pressure & 0.730 & 0.821 & 0.973 \\
\hline \multicolumn{4}{|l|}{ Control variables } \\
\hline Brand experience & 0.847 & 0.861 & 0.876 \\
\hline Order count & 1.004 & 1.004 & 1.003 \\
\hline Age & 0.845 & 0.727 & 0.716 \\
\hline Gender & 0.712 & 0.655 & 0.707 \\
\hline Discount rate & 1.003 & 1.006 & 1.005 \\
\hline Basket size & 1.002 & 1.002 & 1.002 \\
\hline \multicolumn{4}{|c|}{ Model 2 (Interaction effects): } \\
\hline Intercept & 0.852 & 0.027 & 0.017 \\
\hline \multicolumn{4}{|l|}{ Explanatory variables } \\
\hline Purchase channel & 1.006 & 0.935 & 0.984 \\
\hline Time pressure & 0.749 & 0.831 & 1.005 \\
\hline \multicolumn{4}{|l|}{ Interaction effects } \\
\hline Brand experience & 0.824 & 0.838 & 0.932 \\
\hline $\begin{array}{l}\text { Purchase channel } \\
\text { x Brand experience }\end{array}$ & 1.062 & 1.058 & 0.884 \\
\hline $\begin{array}{l}\text { Time pressure } \\
\quad \mathrm{x} \text { Brand experience }\end{array}$ & 0.886 & 0.952 & 0.858 \\
\hline \multicolumn{4}{|l|}{ Control variables } \\
\hline Order count & 1.004 & 1.004 & 1.003 \\
\hline Age & 0.844 & 0.726 & 0.725 \\
\hline Gender & 0.712 & 0.655 & 0.707 \\
\hline Discount rate & 1.003 & 1.006 & 1.005 \\
\hline Basket size & 1.002 & 1.002 & 1.002 \\
\hline
\end{tabular}

\subsection{Contributions to Research}

Our study is positioned at the intersection of marketing and IS literatures. By analyzing a large dataset of real consumer purchase and return transactions we provide empirical validation for the research questions posed. We contribute to existing literature in three ways.

First, we extend the existing literature on the consumer decision making process to include returns as an elementary part. Past research has focused on consumer behavior in the pre-purchase stage. Individual differences and situational variables were also mostly analyzed to understand their effect on search and purchasing behavior. We provide empirical validation that the conceptual relationships proposed by Engel, Blackwell, Miniard [5] for post-purchase behavior also apply to product returns.

Secondly, we applied the constructs for fit uncertainty and quality uncertainty in combination with the expectation disconfirmation theory. We are able to explain how product returns in real purchase situations are driven by consumers expectations and uncertainty at the time of purchase. Furthermore, we showed that situational and individual characteristics significantly influence fit uncertainty at the time of purchase. With this we extended the existing literature, which has extensively studied antecedents of product uncertainty, but focused on marketing tools $[12,28]$.

\subsection{Practical implications}

4.3.1. Lessons learned. Consumers with lower product uncertainty at the time of purchase will be less prone to return purchased merchandise. For marketers trying to reduce return rates this research also contains valuable insights in this regard:

1. Consumers who purchase through the mobile channel are more likely to return a product due to product fit reasons.

2. Consumers who are under time pressure are less likely to return product due to product fit issues.

3. Brand experience increase return likelihood in the mobile channel and under time pressure.

4.3.2. Recommendations. Our results also offer practical insights to retailers on how uncertainty perception and product return behavior of consumers is affected. In the past situational factors and individual differences have only found limited attention, also because they cannot be manipulated by retailers directly and therefore do not constitute a direct lever to reduce return rates. Nevertheless, these findings help retailers get a better understanding how consumers' perceived product uncertainty at the time of purchase is influenced. With this knowledge retailers can devise strategies to indirectly influence consumer's return behavior. Influencing consumer decision making indirectly, also called "Digital Nudging" [63] has found growing attention in past years and suggests that consumers can be guided to make better choices with simple changes to the choice framework. In the context of product returns we suggest the following action steps:

1. Encourage purchases through the desktop channel: This will lead to lower return rates, as consumers collect more information online and will 
therefore experience a lower degree of uncertainty at the time of purchase.

2. Reduce surcharge for express delivery: A lower price for express delivery would most likely increase the number of purchases made under time pressure. This has been shown to significantly reduce product return rates due to fit-related reasons.

3. Encourage mobile shoppers to buy new brands: For purchases in the mobile channel brand experience leads to higher return rates. To achieve this recommender systems could suggest items predominantly from other similar brands that the customer does not know yet.

\section{References}

[1] Anderson, E.T., K. Hansen, and D. Simester, "The Option Value of Returns: Theory and Empirical Evidence", Marketing Science 28(3), 2009, pp. 405-423.

[2] Anderson, R.E., "Consumer Dissatisfaction: The Effect of Disconfirmed Expectancy on Perceived Product

Performance", Journal of Marketing Research 10(February), 1973, pp. 38-44.

[3] BBC News, "Clothing sales drive online shopping growth, says ONS - BBC News", 2014.

http://www.bbc.com/news/business-28691147

[4] Bechwati, N.N., and W.S. Siegal, "The Impact of the Prechoice Process on Product Returns", Journal of Marketing Research 42(3), 2005, pp. 358-367.

[5] Blackwell, R.D., P.W. Miniard, and J.F. Engel, Consumer Behavior 9th, South Western, Mason, OH, 2001.

[6] Boyer, K.K., G. Hult, and T. M., "Customer behavior in an online ordering application: A decision scoring model", Decision Sciences 36(4), 2005, pp. 569-597.

[7] Chu, S.-C., and Y. Sung, "Using a consumer socialization framework to understand electronic word-of-mouth (eWOM) group membership among brand followers on Twitter", Electronic Commerce Research and Applications 14(4), 2015, pp. 251-260.

[8] Cooil, B., T.L. Keiningham, L. Aksoy, and M. Hsu, “A Longitudinal Analysis of Customer Satisfaction and Share of Wallet: Investigating the Moderating Effect of Customer Characteristics", Journal of Marketing 71(1), 2007, pp. 6783.

[9] De, P., Y. Hu, and M. Rahman, "Product-Oriented Web Technologies and Product Returns: An Exploratory Study", Information Systems Research 24(4), 2013, pp. 998-1010.

[10] DeSarbo, W.S., J. Park, and V.R. Rao, "Deriving joint space positioning maps from consumer preference ratings", Marketing Letters 22(1), 2010, pp. 1-14.

[11] Dholakia, R.R., M. Zhao, and N. Dholakia,

"Multichannel retailing: A case study of early experiences", Journal of Interactive Marketing 19(2), 2005, pp. 64-74.

[12] Dimoka, A., Y. Hong, and P.A. Pavlou, "On Product Uncertainty in Online Markets: Theory and Evidence", MIS Quarterly 36(2), 2012, pp. 395-426.

[13] Dowling, G., and R. Staelin, "A Model of Perceived Risk and Intended Risk-Handling Activity", Journal of Consumer Research 21(1), 1994, pp. 119-134.
[14] Engel, J.F., D.T. Kollat, and R.D. Blackwell, Consumer Behavior, Holt, Rinehart, and Winston, New York, NY, 1968.

[15] Engel, J.F., D.T. Kollat, and R.D. Blackwell, Consumer Behavior, 1990.

[16] Forbes, "The Ticking Time Bomb Of E-commerce Returns", 2018.

https://www.forbes.com/sites/stevendennis/2018/02/14/theticking-time-bomb-of-e-commerce-returns/\#59b0835c4c7f

[17] Foscht, T., K. Ernstreiter, C. Maloles, I. Sinha, and B. Swoboda, "Retaining or returning?", International Journal of Retail \& Distribution Management 41(2), 2013, pp. 113-134. [18] Foscht, T., K. Ernstreiter, C. Maloles III, I. Sinha, and B. Swoboda, "Retaining or returning? Some insights for a better understanding of return behaviour", International Journal of Retail \& Distribution Management 41(2), 2013, pp. 113-134.

[19] Francken, D.A., "Postpurchase Consumer Evaluations, Complaint Actions and Repurchase Behavior", Journal of Economic Psychology 4, 1983, pp. 273-290.

[20] Ghose, A., "Internet Exchanges for Used Goods: An Empirical Analysis of Trade Patterns and Adverse Selection", MIS Quarterly 33(2), 2009, pp. 263-291. [21] Ghose, A., A. Goldfarb, and S.P. Han, "How is the mobile internet different? Search costs and local activities", Information Systems Research 24(3), 2013, pp. 613-631. [22] Ghose, A., M.D. Smith, and R. Telang, "Internet exchanges for used books: An empirical analysis of product cannibalization and welfare impact", Information Systems Research 17(1), 2006, pp. 3-19.

[23] Ghose, A., and Y. Yao, "Using Transaction Prices to Re-Examine Price Dispersion in Electronic Markets", Information Systems Research 22(2), 2011, pp. 269-288. [24] Greene, W.H., Econometric Analysis, Pearson Prentice hall, Upper Saddle River, NJ, 2008.

[25] Gu, Z. (Jane), and G.K. Tayi, "Consumer mending and online retailer fit-uncertainty mitigating strategies", Quantitative Marketing and Economics 13(3), 2015, pp. 251282.

[26] Hauke, J., and T. Kossowski, "Comparison of values of pearson's and spearman's correlation coefficients on the same sets of data", Quaestiones Geographicae 30(2), 2011, pp. 87-93.

[27] Hauser, J.R., G.L. Urban, and B.D. Weinberg, "How consumers allocate their time when searching for information", Journal of Marketing Research XXX(November), 1993, pp. 452-466.

[28] Hong, Y.K., and P.A. Pavlou, "Product Fit Uncertainty in Online Markets : Nature , Effects , and Antecedents", Information Systems Research 25(2), 2014, pp. 328-344. [29] Hsiao, L., and Y.-J. Chen, "Returns Policy and Quality Risk in E-Business", Production and Operations Management 21(3), 2012, pp. 489-503.

[30] Ilesias, O., J.J. Singh, and J.M. Batista-Foguet, "The role of brand experience and affective commitment in determining brand loyalty", Journal of Brand Management 18, 2011, pp. 570-582.

[31] Janakiraman, N., H.A. Syrdal, and R. Freling, "The Effect of Return Policy Leniency on Consumer Purchase and Return Decisions: A Meta-analytic Review", Journal of Retailing 92(2), 2016, pp. 226-235. 
[32] Kang, M., and K. Johnson, "Identifying characteristics of consumers who frequently return apparel", Journal of Fashion Marketing and Management 13(1), 2009, pp. 37-48. [33] Kirmani, A., and A.R. Rao, "No pain, no gain: A critical review of the literature on signaling unobservable product quality", Journal of Marketing 64(2), 2000, pp. 66-79. [34] Klapproth, F., "Time and decision making in humans", Cognitive Affective \& Behavioral Neuroscience 8(4), 2008, pp. 509-524.

[35] Kopalle, P.K., and D.R. Lehmann, "The effects of advertised and observed quality on expectations about new product quality", Journal of Marketing Research 32(3), 1995, pp. 280-290.

[36] Kroll, A., "Underwear of uncertain origin", Pacific Standard, 2017. https://psmag.com/magazine/underwear-ofuncertain-origin

[37] Lawton, C., "The War on Returns", Wall Street Journal, 2008. https://www.wsj.com/articles/SB121020824820975641 [38] Lee, D.H., "An Alternative Explanation of Consumer Product Returns from the Postpurchase Dissonance and Ecological Marketing Perspective", Psychology \& Marketing 32(1), 2015, pp. 49-64.

[39] Lee, L., and C.I. Tsai, "How Price Promotions Influence Postpurchase Consumption Experience over Time", Journal of Consumer Research 40(5), 2014, pp. 943-959.

[40] Leeflang, P.S.H., D.R. Wittink, M. Wedel, and P.A. Naert, Building Models for Marketing Decisions, Springer Science+Business Media, Dordrecht, 2000.

[41] Liang, T.-P., and J.-S. Huang, "An empirical study on consumer acceptance of products in electronic markets : a transaction cost model", Decision Support Systems 24(1), 1998, pp. 29-43.

[42] Lohse, T., J. Kemper, and M. Brettel, "How Online Customer Reviews Affect Sales and Return Behavior - an Empirical Analysis in Fashion E-Commerce", ECIS 2017 Proceedings, (2017), 2635-2644.

[43] Maity, D., and T. Arnold, "Search: An Expense or an Experience? Exploring the Influence of Search on Product Return Intentions", Psychology \& Marketing 30(7), 2013, pp. 576-587.

[44] Maule, A.J., and A.C. Edland, "The effects of time pressure on human judgment and decision making", In R. Ranyard and O. Svenson, eds., Decision making: Cognitive Models and Explanations. Routledge, London, 1997, 189204.

[45] Minnema, A., T.H.A. Bijmolt, S. Gensler, and T. Wiesel, "To Keep or Not to Keep: Effects of Online Customer Reviews on Product Returns", Journal of Retailing 92(3), 2016, pp. 253-267.

[46] Mukhopadhyay, S.K., and R. Setaputra, "A dynamic model for optimal design quality and return policies",

European Journal of Operational Research 180(3), 2007, pp. 1144-1154.

[47] Okazaki, S., and F. Mendez, "Perceived Ubiquity in Mobile Services", Journal of Inter 27(2), 2013, pp. 98-111.

[48] Oliver, R.L., "Effect of expectation and disconfirmation on postexposure product evaluations: An alternative interpretation.", Journal of Applied Psychology 62(4), 1977, pp. $480-486$.

[49] Oliver, R.L., "A cognitive model of the antecedents and consequences of satisfaction decisions", Journal of
Marketing Research 17(4), 1980, pp. 460-469.

[50] Pavlou, P.A., H. Liang, and Y. Xue, "Understanding and mitigating uncertainty in online environments: a principalagent perspective", MIS Quarterly 31(1), 2006, pp. 105-136. [51] Pavlou, P.A., H. Liang, and Y. Xue, "Understanding and mitigating uncertainty in online environments: a principalagent perspective", MIS Quarterly 31(1), 2007, pp. 105-136. [52] Petersen, A.J., and V. Kumar, "Perceived Risk, Product Returns, and Optimal Resource Allocation: Evidence from a Field Experiment", Journal of Marketing Research 52(2), 2015, pp. 268-285.

[53] Petersen, J.A., and V. Kumar, "Are Product Returns a Necessary Evil? Antecedents and Consequences", Journal of Marketing 73(3), 2009, pp. 35-51.

[54] Porter, M.E., "Harvard Business Review on Measuring Corporate Performance", Measuring Business Excellence 3(1), 1999, pp. 63-63.

[55] Powers, T.L., and E.P. Jack, "The Influence of Cognitive Dissonance on Retail Product Returns", Psychology \& Marketing 30(8), 2013, pp. 724-735. [56] Rao, S., E. Rabinovich, and D. Raju, "The role of physical distribution services as determinants of product returns in Internet retailing", Journal of Operations Management 32(6), 2014, pp. 295-312.

[57] Saleh, K., "E-commerce Product Return Rate - Statistics and Trends", 2018.

https://www.invespcro.com/blog/ecommerce-product-returnrate-statistics/

[58] Shah, D., V. Kumar, and K.H. Kim, "Managing Customer Profits: The Power of Habits", Journal of Marketing Research (JMR) 51(6), 2014, pp. 726-741. [59] Shulman, J.D., a. T. Coughlan, and R.C. Savaskan, "Optimal Restocking Fees and Information Provision in an Integrated Demand-Supply Model of Product Returns", Manufacturing \& Service Operations Management 11(4), 2009, pp. 577-594.

[60] Shulman, J.D., M. Cunha, and J.K. Saint Clair, "Consumer Uncertainty and Purchase Decision Reversals: Theory and Evidence", Marketing Science 34(4), 2015, pp. 590-605.

[61] Speights, D., and M. Hilinski, "Return Fraud and Abuse : How to Protect Profits", The Retail Equation 17, 2013, 1-6.

https://www.theretailequation.com/Retailers/images/public/p dfs/white papers/wp TRE4013 WhitePaper ReturnFraud101 Feb2013.pdf.

[62] Weathers, D., S. Sharma, and S.L. Wood, "Effects of online communication practices on consumer perceptions of performance uncertainty for search and experience goods", Journal of Retailing 83(4), 2007, pp. 393-401.

[63] Weinmann, M., C. Schneider, and J. Brocke, "Digital Nudging", Business \& Information Systems Engineering 58(6), 2016, pp. 433-436.

[64] Wood, S.L., "Remote Purchase Environments: The Influence of Return Policy Leniency on Two-Stage Decision Processes", Journal of Marketing Research 38(2), 2001, pp. 157-169.

[65] Yalabik, B., N.C. Petruzzi, and D. Chhajed, "An integrated product returns model with logistics and marketing coordination", European Journal of Operational Research 161(1), 2005, pp. 162-182. 


\section{Appendix}

\subsection{Methodology}

Table 3 gives an overview over the descriptive statistics obtained for the measures describes above. A slight majority of purchases is made via the mobile channel $(52 \%)$ and time pressure is only observed in $2 \%$ of the cases. Since the dependent variable is categorical in nature we run a multinomial logistic regression analysis in $\mathrm{R}$ following a widely used approach in consumer behavior research with a discrete choice settings (e.g. [40]).

Consumers have a discrete choice regarding their post-purchase decision reversal. They can either return the product or keep it [17]. In case consumers decide to return the product, they can state the primary reason for their return or decide not to disclose this information.

\section{Table 3. Des criptive $s$ tatis tic}

\begin{tabular}{lcccc}
\hline Variable & Mean & SD & Min & Max \\
\hline $\begin{array}{l}\text { 1. Return reason }\left(\beta_{1}\right) \\
\text { 2. Purchase channel }\end{array}$ & & & & \\
- [mobile=1] $\left(\gamma_{1}\right)$ & 0.48 & 0.71 & 0 & 1 \\
3. Time pressure & & & & \\
- [yes $=1]\left(\gamma_{2}\right)$ & 0.98 & 0.19 & 0 & 1 \\
4. Brand experience & & & & \\
- [yes $=1]\left(\gamma_{3}\right)$ & 0.22 & 0.59 & 0 & 1 \\
5. Order count $\left(\gamma_{4}\right)$ & 37.44 & 56.56 & 1 & 974 \\
6. Age [">30" $=1]\left(\gamma_{5}\right)$ & 39.80 & 20.36 & 14 & 100 \\
7. Gender - [yes $=1]\left(\gamma_{6}\right)$ & 0.20 & 0.56 & 0 & 1 \\
8. Discount rate $\left(\gamma_{7}\right)$ & 0.07 & 0.17 & 0 & 1 \\
9. Basket size $\left(\gamma_{8}\right)$ & 305.92 & 260.10 & 1 & 5059 \\
\hline
\end{tabular}

In our model we consider the following 4 alternatives $j=\{$ No return, Product fit, Product quality, other/no response $\}$ that the customer can choose from. In unordered choice models, variables can be either alternative specific or individual specific [24]. In our model all variables are individual specific and not influenced by the selected outcome variable. In the given case the probability of customer i to select return reason Yi can be expressed as follows:

$$
\operatorname{Prob}\left(j=Y_{i}\right)=\frac{\exp \left(\beta x_{i j}\right)}{\sum_{k \in j_{i}} \exp \left(\beta x_{i k}\right)}
$$

$Y_{i}$ denotes the discrete value of the dependent variable. Table 4 provides the correlations of the input variables. Since variables do not have the interval format Spearman's correlation coefficient is applied [26]. Correlation between variables is modest, with the highest absolute correlation existing between purchase channel and customer age $(|r|<0.19)$.
Table 4. Correlation matrix

\begin{tabular}{lrrrrrrrr}
\hline Variable & 2 & 3 & 4 & 5 & 6 & 7 & 8 & 9 \\
\hline $\begin{array}{l}\text { 2. Purchase channel - } \\
\text { mobile }\left(\gamma_{1}\right)\end{array}$ & 1.00 & 0.02 & 0.04 & 0.03 & -0.19 & 0.01 & 0.01 & -0.03 \\
3. Time pressure & & & & & & & & \\
- yes $\left(\gamma_{2}\right)$ & 0.02 & 1.00 & 0.01 & 0.01 & -0.01 & -0.02 & -0.01 & 0.00 \\
4. Brand experience - & & & & & & & & \\
yes $\left(\gamma_{3}\right)$ & 0.04 & 0.01 & 1.00 & 0.17 & -0.01 & -0.02 & 0.00 & -0.06 \\
5. Order count $\left(\gamma_{4}\right)$ & 0.03 & 0.01 & 0.17 & 1.00 & 0.13 & 0.13 & -0.02 & 0.03 \\
6. Age $\left(\gamma_{5}\right)$ & -0.19 & -0.01 & -0.01 & 0.13 & 1.00 & 0.02 & 0.01 & -0.04 \\
7. Gender $\left(\gamma_{6}\right)$ & 0.01 & -0.02 & -0.02 & 0.13 & 0.02 & 1.00 & -0.03 & 0.03 \\
8. Discount rate $\left(\gamma_{7}\right)$ & 0.01 & -0.01 & 0.00 & -0.02 & 0.01 & -0.03 & 1.00 & -0.11 \\
8. Basket size $\left(\gamma_{8}\right)$ & -0.03 & 0.00 & -0.06 & 0.03 & -0.04 & 0.03 & -0.11 & 1.00 \\
\hline
\end{tabular}

$1 . \mathrm{p}<.001$ for all values

2. All binary variables were coded as $\{0,1\}$-duplets.

3. The highest correlation between two variables is .19 . 